\title{
Design Students Blogging: A Case Study of Identity and Convenience
}

\author{
Sancha de Burca \\ University of Kent at K College \& The Graphic Design Project
}

This paper describes a case study, initiated in 2011, of the use of blogs in the research and development work of graphic design students studying for the University of Kent's HND and BA (Hons) Top Up, situated at K College in Tonbridge. Initially to develop the professional identities of blogging students, the project evolved into an exploration of the affordances of blogging as a convenience that resulted in raised levels of design thinking. These affordances included improved written skills, contemporaneous posting and ideas development and the production of knowledge in the form of instructional 'how-to' posts. This paper attempts to explore the logistics of how these best practices were enabled.

\section{Background}

The use of blogs in the Kent students' graphic design process was first inspired by a talk by Jim Turner of John Moores University at the University of Greenwich e-learning conference in 2011. Turner spoke about blogging as an activity that raised awareness of the blogger's own identity. In particular, he had undertaken a research study with fine art students and found that the use of blogs helped increase their own perception of themselves as 'professionals' (Turner, 2011).

Turner also emphasised that the professionalisation of these identities occurred only when students used real-life blogs, rather than in-house institutional blogs, such as Moodle. This was because 'real' blogs had potential opportunities for 'authentic' audience reaction, especially the notion that other professionals were watching. Turner's students also liked to 'lurk' and to view what was happening on the blogs of others (Turner, 2011).

A few of the students on the graphic design programmes of the University of Kent were already voluntarily beginning to use blogs as part of their design work and were submitting these as evidence of their bodies of work. The staff team had always encouraged learners to find their own best practice within their design processes. It was observed that some learners challenged by written work, such as dyslexics, also found blogging preferable to pen or pencil work.

In September 2011, the new cohort was encouraged to use blogs for evidencing the body of work that led up to a final design piece: research, analysis, development of ideas, evaluation and reflection. They were invited to do this either in conjunction with traditional sketchbooks or instead of sketchbooks. Some preferred conventional processes, choosing not to blog.

\section{Methodology}

In October 2011, after an initial period when students who had not previously blogged rehearsed blogging, the new cohort, both bloggers and non-bloggers, was surveyed. This initial survey posed questions about how students experienced the change to blogging and whether or not they found this a positive method. It was also driven by what Turner had discovered (2011) and solicited the bloggers' own impressions of working in a potentially 
public domain, asking how they reacted to the presence of others and how they perceived their own consequential growing professionalism.

The results showed that, while bloggers enjoyed using blogs and saw them as a means of improving their design process, they had little or no contact with or interest in the wider blogging community and were not aware of becoming more professional. See the observations below for more detail.

At the end of the academic year, this same cohort was surveyed again, along with the two cohorts in the years above (many of whom asked to be included and who had started blogging in response to the first-year trial). By this time, it was realised that some of the Turner-driven community questions did not necessarily apply to our cohorts and so the logistical thrust of this survey was to glean feedback about design students' experiences in their months of blogging and about how blogs were practically useful to them.

As well as the two surveys, informal focus groups were used, together with additional ad hoc discussions. The latter were useful in allowing individual learners to volunteer unsolicited comments, especially about why they had chosen to blog (or not), and in encouraging learners to express their views about specific parts of the blogs, such as the 'how-to' posts. Explorations of the blogs themselves were made, to observe and investigate individual uses made of them. Overall, the implications for good practice of the use of blogs in teaching, learning and the design process have been an integral part of the case study, observations for which continued into 2013.

A University of Kent ethics protocol was initiated at the time of the surveys as part of the author's PGCHE study. Students were aware that their blogs were being scrutinised for a case study and individual permissions were sought for the use of examples in conference talks and publications.

\section{Observations}

\section{Blogging in general}

During the first term, there seemed, informally, to be a correlation between the students who blogged and the students who gained higher grades. The grades of the first-year cohort were immediately slightly above average. However, any direct correlation between the act of blogging and higher grades remains unproven. Turner had pointed out that extrovert students took to blogging more easily (2011) and this factor may account for the inclination to post effectively amongst this gregarious group.

Blogging grew in popularity amongst the cohorts as a peer-led dynamic. A second-year student noted that it was a much easier process than sketchbook-keeping and that he meant that in a 'meaningful way, not just a lazy way'. Blogs were felt to be more relevant to the designer role and it may therefore be that this design- and computer-oriented group took to blogging more easily than other disciplines might do.

Design companies use blogs as an attachment to their regular websites to demonstrate their informal and friendly side, to discuss their work in progress or to promote their identity with 'everyday' items and thus gain more clients (Sheldon, 2008). Moreover, blogs can easily be 
regularly updated, are therefore seen as fresh and new (Mathers, 2011) and can gather important feedback, so vital to any company in the social networking era of advertising (Sheldon, 2008).

\section{Design Phase 2, After Feedback}

April 18, $2013 / / \quad 0$

\begin{abstract}
After first initially creating my groups semiotics poster I decide it would be really beneficial to have some people give me feedback on it and they really liked the design there were just a few things that needed to be changed and moved about to make the poster a final outcome.
\end{abstract}

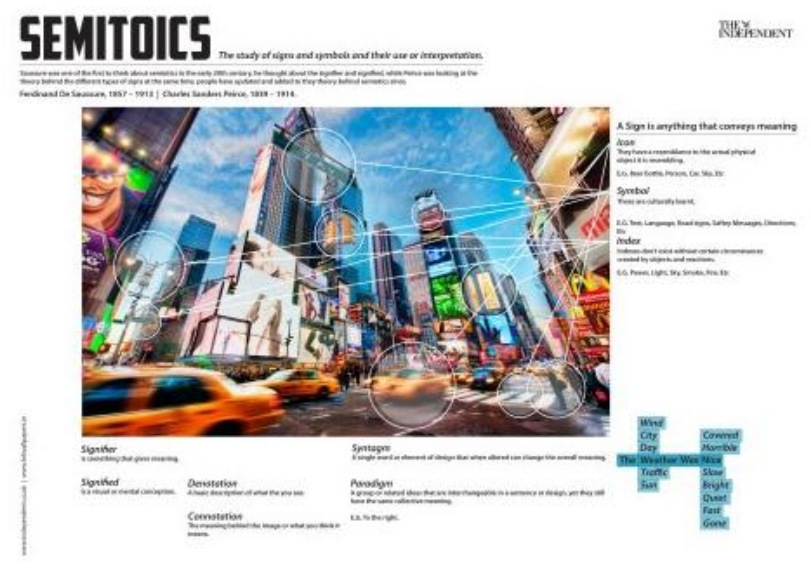

\footnotetext{
The photo below shows the feedback that I was given from my teacher and this is the first copy of the design, the things that she pointed out on that I should and needed to improve were as following:

- The history information underneath the title is too long it needs to be broken up and adjusted.

- The different aspects of semiotics need to have a bit more information to help the reader understand semiotics better.

- There could possible be some more images around the large central image.

- I need better examples for the sign's sections.
}

From this I adjusted everything to a stage were I thought it a finished product, but even now I have just seen a couple of things that I need to

Blog of student AR showing typical design process account and ongoing evaluations

\section{Writing skills}

Academic and blogging commentators are unanimous on one topic: that blogging is an ideal way of practising and developing writing skills (Cassuto, 2011; Saper, 2006, cited in Kirkup, 2010). Blog posts are not random, quick or lacking in thought. Indeed, bloggers consider the completeness of each post as 'a rounded piece'. Writing of concise and 'finished' texts is practised (Kirkup, 2010). Many writers from the academic community also agree that blogging is a useful way of shaping ideas and of gleaning feedback and ideas from others. Becoming more confident in the sharing of ideas is a side effect of blogging (Kirkup, 2010). In this way, blogs fall into the overall notion of the shared, community body of collective knowledge and learning that is re-shaped by users (Littlejohn, 2011). 
The idea that blogs can drive specific identities appears across much of the literature on writing skills and blogging. Gregg (2006, cited in Kirkup, 2010) states that all blogging is 'performative writing', in that it has an audience, and Ewins (2005, cited in Kirkup, 2010) refers to 'multiphrenic' identities, when individuals are using a range of media, styles and narratives in which to write or occur. In relation to academics who blog, Kirkup also states that blogging is a kind of 'continuous development of the professional self', in which identities morph and grow as blogging leads in new directions. For academics, this is an alternative to the peer-reviewed paper, permitting new areas of the public self to be aired (Kirkup, 2010).

The surveyed Kent students were asked: 'In what ways do you feel that your blog has helped you to develop skills of writing or analysis?' Most of the students surveyed agreed with the points mentioned previously that the "roundedness" and frequency of posting helped them to construct well-written texts. They also liked the fact that posts could be edited or added to.

\section{Contemporaneous posting}

Problems with traditional sketchbook work were that learners could spend undue time collecting and collating research in the form of print-outs and objects. These needed to be physically glued into the book and annotated in a way that showed that meaningful conclusions were being drawn. However, students often focused upon their design process and left annotation until the end of the project. This rendered the notes almost useless, as they should have been contemporaneous with the thought processes in order for them to work as development tools and ideas-generators. Late notes were often lacking in critical value or relevant inspiration. Sketchbook work could thus become laborious and even, to an extent, pointless.

In contrast, the first positive outcome, and one that had been an aim of the blogging activity, was that the blog posts were made on a regular basis, often, as one student described, 'done from my phone on the way home'. Now, blogging students were posting thoughts at more appropriate times and it was felt that this played back into the creative process in an effective way, enabling more meaningful problem-solving, which, in turn, made more effective design pieces and helped best practices amongst bloggers to develop.

\section{Convenience}

In the initial survey, the results showed that professional identity was not an overt or conscious issue amongst the bloggers. Instead, the concept of convenience emerged as a motivating factor. For example, the groups were asked in what ways they felt a blog was better than a sketchbook, or not. The overwhelming answer was that everything was together in a blog and all you needed was the internet to access it. Convenience outweighed any other reason for preferring them. Again, students felt that they could work into them contemporaneously, such as on the way home, and that they didn't forget to add notes. They could blog 'on the job', while researching online or using design software, simply by opening their blogs in a new window. This, in turn, helped their design process by actively enabling deeper consideration of issues. 
Furthermore, an able student mentioned that, in a blog, the post physically expanded to accommodate text and image, allowing for writing of any length, whereas a sketchbook limited the writing to available page space. His point was echoed across the blogging cohorts. This might account for the raised levels of analysis that were noted across the year and certainly relates to the roundedness of blog posts mentioned below.

\section{Format and purpose of blogs}

Academic blogs, states Lee Skallerup Besette (Moorehead State University, Kentucky, 2011), take three different forms: the journal, sharing thoughts; the 'how-to' blog-sharing advice or good practice, such as teaching notes; the reflective blog. It is possible that the blogs of the Kent students, instigated because of the need to evidence bodies of research and development for specific programme learning outcomes, could fall into any or all of these categories as cognitive and technical parts of the design process are discussed.

Specifically, there are two realms in which these cohorts might blog: the professional realm of the graphic designer and the academic realm of the H.E. student (as novice academic). Much of what is posted is auto-ethnographic in terms of being a critical record of own practice.

However, many of the blogging students also posted 'how-to' articles, rehearsing their technical and practical experiments. Members of the Kent cohort stated that they used and appreciated outside blogs' 'how-to' posts and wanted to reciprocate, thus actively and knowingly becoming producers of knowledge in the wider community.

Initially, students' own evaluations of work in progress and, especially, summative project evaluations were used more within the blogs than within the sketchbooks, but this might simply have been the result of the ease of cutting and pasting an evaluative set of questions from a Word document provided on Moodle. More recently, a rise in self-initiated evaluation has been seen, with target-setting posts appearing immediately after events such as interim 'crits' or tutorials. Again, this is considered to be best practice in the design process. 

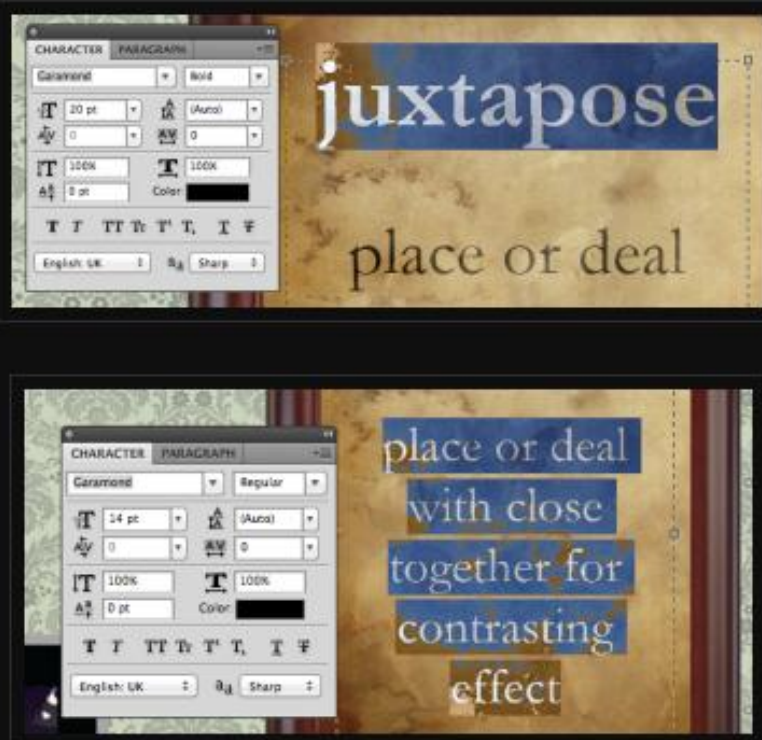

Step 24: As you may have noticed from the previous close-ups of the type, it looks a bit faded in sections, which I did to blend it into the paper to add to the realism of the aged feel. To do this I bought up the Layer Styles menu by double-clicking on the type layer, and using the Blend If function, the settings of which can be seen below. To split the highlights section so half can be dragged across the screen, hold the alt/option key while dragging it.
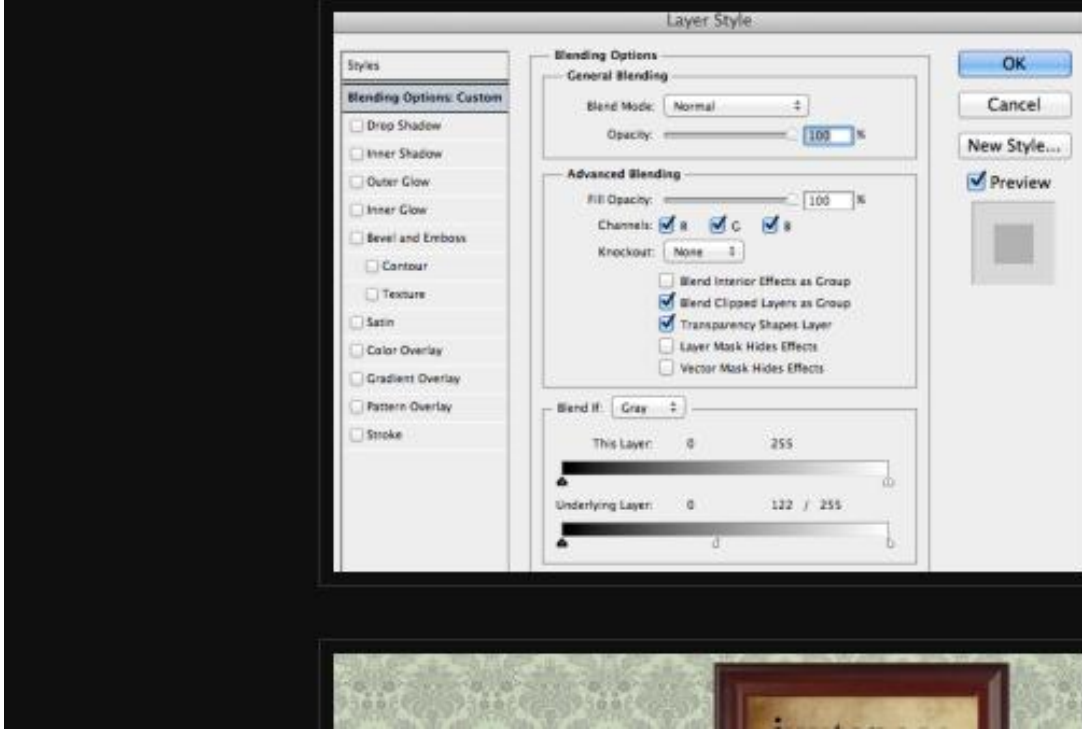

Blog of student AG showing a How-to tutorial

\section{Ownership}

A further positive outcome was that some students were adding extras to their blogs, such as accounts of exhibition visits and other enrichment activities that were not directly part of the design projects, so blogs became journals and widened the blogger's identity as a reporter of design and culture. Many of these were personal research visits, rather than institution-instigated ones. In this way, learners took ownership of their own blogs, expanding and customising them. One blogger, who subsequently started many diverse blogs, stated that she 'loved' her first blog and felt inspired to run it. 
Bloggers also personalised and indeed professionalised their blogs by including portfolio pages, the links to which can be sent directly to clients and employers when students are seeking work or internships. More recently, bloggers have made their own knowledgecommunity connections by using their blogs to advertise and link to their other social networks, such as the design portfolio sites, Behance and Tumblr. Although the bloggers surveyed did not report feeling more professionalised, they were nevertheless independently carrying out professional networking and customising activities.



Blog of student LO showing network links

\section{Community}

Surprisingly, none of the students in the first survey felt any connection to a 'community' or reported any links with audiences. Turner's student subjects had been encouraged to feed into each other's blogs, whereas the Kent students would ask only the tutors to view their blog work. More recently, comments have been made by strangers, with the concomitant nuisance of spam. Also, some learners have been requesting peer assistance via the 'comments' section of their blogs. 
The second survey set of questions was less concerned with student identity in the public realm, as it was now understood that this was not important to the group. When asked what they thought about their blogs being in the public domain, many of the bloggers worried about others stealing their designs. Some had taken to marking their own images with a named watermark. 'Fair use' in referencing the work of others remains an unclear issue and bloggers use 'links out' when in doubt. Some events, such as Somerset House's 'Pick Me Up' exhibition, encourage blogging, whereas others, such as the artists' books section of the Victoria and Albert Museum, decline requests to use visited works in blogs on the grounds that individual artists, not the museum, hold the copyright.

However, the notion of a 'lurking' or active audience is very powerful in blogging. Frequently, no comments are posted, but the assumption of a hidden but potential audience influences how and what the blogger posts. Bloggers have reported trying to make their posts more accessible for imagined audiences, or of being 'attention-hungry' (Kirkup, 2010). Kirkup's study found that all of her blogging subjects wished to gain an audience and engage in dialogue. For Turner's study, it was the idea of an audience of peers and professionals that drove the blogger's identity from 'student' to 'fellow professional' (Turner, 2011).

\section{Signature Pedagogy}

An unexpected side effect of the blogging activity has been the alteration of the staff mode of working and especially of assessing. Blogs have almost entirely replaced sketchbooks, though some students still use them for all back-up work and many for thumbnail ideas which are then scanned into the blogs. Design work that is more finalised can be included in the blog and more computer processes are detailed, thanks to added screenshots. Staff can access a learner's body of evidence at any time from any place, rather than just when a learner with sketchbook is physically present, and links can be sent to examiners ahead of their visits. Feedback can easily be provided via the 'comments' section and in this way work that needs development can be 'caught'. However, staff have noted that they often email or speak personally to a learner when remedial work is necessary, rather than add it as a blog comment (although comments are moderated by the blogger and do not automatically appear in public). When staff do comment, they do so via the course blog. However, it is not the fact of commenting in public that drives personal conversations, but rather the chance to engage in an unmediated dialogue to push design work forward quickly.

\section{Conclusion}

The surveyed learners reported the blogging process to be organised, efficient, helpful, aesthetically smart and of-the-moment, in that most designers are using blogs. In conclusion, it cannot be said that blogging students developed their professional identities overtly. Yet the bloggers moved into the comforting sense that blogging was part of the design community of practice; was developing their design processes, helping them to keep a record of interesting resources and keeping them up-to-date. This is encouraging in terms of their later moving out into the industry. Via voluntary acts of best practice, such as taking ownership of blogs, producing knowledge in a public arena and setting up working networks, it can be suggested that professionalisation was nevertheless taking place. Specifically, technological convenience was a motivating factor, enabling learners to work in more efficient and effective ways which allowed such best practices as these to develop as a natural consequence. 


\section{References}

Adenekan, Shola, (2005), Academics give lessons on blogs, BBC News. Available at: http://newsvote.bbc.co.uk/mpapps/pagetools/print/news.bbc.co.uk/2/hi/uk_news/eduction/41 94669.stm (Accessed 10 March 2012).

Cassuto, L. (2011) 'The measure of blogging: the use of different media in academic publishing.' The Guardian Higher Education Network, 31 August 2011. Available at: www.theguardian.co.uk/higher-education-network/blog/2011/aug/31/print-blog-academicpublishing (Accessed 10 March 2012).

Cohen, D. (2008) Evans and Cebula on Academic Blogging. Available at: www.dancohen.org/2011/11/08/evans-and-cebula-on-academic-blogging/ (Accessed 10 March 2012).

Framer, B., Yue, A. and Brooks, C. (2008) 'Using blogging for higher order learning in large cohort university teaching: A case study.' Australasian Journal of Educational Technology, 24(2), 123-136.

Kaye, B.(2007), 'Blog Use Motivations.' In Tremayne, M. (ed) Blogging, Citizenship, and the Future of Media, Routledge, New York, pp 127-148.

Littlejohn, A (2011) 'Charting and collective learning.' Own notes from Greenwich APT keynote speech, 7 July 2011.

Littlejohn, A. (2012) Charting collective knowledge: supporting self-regulated learning in the workplace, 2012, Emerald Group Publishing Ltd. Available at: http://www.emeraldinsight.com/journals.htm?articleid=17010279\&show=abstract (Accessed 30 October 2013).

Kirkup, G. (2010) 'Academic Blogging: academic practice and academic identity', London Review of Education, Institute of Educational Technology, The Open University, Milton Keynes. Available at:

http://www.tandfonline.com/doi/abs/10.1080/14748460903557803\#.U84fDatwbml (Accessed 9 March 2012).

Mahers, A (2011) 6 Easy Ways of Using Writing on the Internet to Promote Yourself, Red Lemon Club. Available at: http://www.redlemonclub/traffic/6-easy-wayss-of-usng-writing-onthe-internet-to-promote-yourself (Accessed 10 March 2012).

O’Donnell, M. (2006) 'Blogging as Pedagogic Practice: Artefact and Ecology'. Asia Pacific Media Educator, Issue No 17, Dec 2006, pp 5- 19.

Sheldon, G (2008) Start Your own Graphic Design Business, Entrepreneur Press. Available at: http://books.google.co.uk/books?id=umbwaDWIY8oC\&pg (Accessed 10 March 2012).

Skallerup Bessette, L. (2011) Profiling the academic blogosphere, Guardian Professional Higher Education Network. Available at: http://www.theguardian.co.uk/higher-educationnetwork/blog/oct /24/academic-blogging-landscape (Accessed 10 March 2012).

The Times Higher Education (2008) 'By the Blog: academic tread carefully.' Available at: http://www.timeshighereducation.co.uk/403827.article (Accessed 21 October 2011) 
Turner, J. (2011) 'Blogging and Identity'. Own notes from Greenwich University e-learning conference talk, 7 July 2011.

SSRC (2009) 'The Immanent Frame, 2.Blogging and academia.' Available at: http://www.blogs.ssrc.org/toff/religion-blogosphere/religion-blogoshpere-2/ (Accessed 10 March 2012).

Marshall scholar in theoretical physics - Name withheld (2007) 'The Value of Blogs in Academia: An American physics student in England, 2007.' Available at: http://fliptomato.wordpress.com/2007/02/11the-value-of-blogs-in-academia/ (Accessed 10 March 2012). 